\title{
A NOTE ON DWORKIN'S INTERPRETIVE STAGES
}

\author{
Yrd. Dog. Dr. Ayşen FURTUN*
}

Interpretation assumes a relation between the object involved and the purpose of the interpreter imposed upon it; if there were no such assumption in consideration, the interpreter which is surely a rational and a humane-being (cf. Dworkin's arguments about integrity as a moral ideal and the political obligation observed in small fraternal-relations based associations which shall be examined below) would be a mere quoter, surely presupposing behind even this act of his a text written by someone whom he is voicing now and surely even in this case with his own addition to it whether he desires to or not! depending on the purpose why he is making that very quotation; that is why he is acting in that very special way, that is again acting in accordance with some lines determined beforehand by a writer in the "text" form which requires to be realised, that is, quoted, acted, that is again, voiced up at that very moment in regards the problem that makes it essential and urgent to be done so! So the relation in the interpretive task is not one of copying but of original bearing; put otherwise, as the assumption requires, people are considered to be capable of interpreting the universe they live in together with the objects making up that university, that is, their supposed to be interpretation in this case is not something to be obeyed to, that is again in literary form, lines to be quoted, -but even in that case it poses a question of which lines are to be quoted, definitely based on a determination of some purpose which ought to be fit with the question at hand!- with no individual intellectual participation, even if the very thing to be complied to were of certain and ultimate rationale! (cf. Consider the regimes where utopic intellect is made to be the course of conduct to be followed

* Dr. Ayşen Furtun is Assistant Professor in Ankara University Law Faculty in the Department of Philosophy and Sociology of Law. 
to without alterations, modifications and participation and what soever!) We should compare and contrast this point with the point mentioned above, that of Dworkin's political aspect of his interpretive theory which comes out as the "community of principal" where each individual is held responsible equally in regards to oneanother and furthermore beyond the patterns compromised upon. (cf. Dworkin's arguments in regards compromising process where he asserts that "checker-board rules are not morally good enough to build a legal system upon in regard law as integrity observed in "past decisions of legislatures and judiciaries" discussed further below)

Returning to our point now, the quotation from a text performed by an actor and the act that requires the author of it to put it in textual form giving it a substance to be referred to whenever required -once born thus- is of the very same pattern of relation Dworkin is ascribing to when he is evaluating his concept of "interpretation which seeks to establish an equilibrium between the preinterpretive account of a social practice and a suitable justification of that practice" saying that he has "borrowed the concept of equilibrium from Rawls" which he actually deploys differently than that of Rawls' account of reasoning about justice seeking "the equilibrium of intuitions about justice and a formal theory uniting these intuitions"'. But the point we refer to, in Dworkin's terms is that, "Interpretation of a social practice seeks equilibrium between the justification of the (social) practice and its post-interpretive requirement"2. Thus the pre-interpretive stage, which we shall examine below, responds to the social setting the writer is inspired to put his work in words, that is, "writing", and actually he does this in a completed task of the "actual text of the play". It is worth noting that if we were to suffice with the pattern of Rawls, in literary terms that would fit the style of a "novel" with no stage performan$c e$, where the justification process providing the very equilibrium need not be checked upon once more as the post-interpretive stage in Dworkinian model requires it to be. This point corresponds again to Dworkin's model of "Integrity versus checkerboard rules" of pragmatic compromise whereby the justification process of a text in much less "vague definition" -except that of certain lines observed in the pre-interpretive stage-is examined once again against another pattern beyond the acknowledged ones of observation in

1. Dworkin, R. Law's Empire, Fontana Press, 1986, p. 424.

2. Dworkin, R. Law's Empire, Fontana Press, 1986, p. 424. 
the compromising process, which is the mere ideal of integrity in Dworkinian terms, which again corresponds to the common principals inherent yet not yet acknowledged -behind the patterns observed (cf. Dworkin's exemplary of Neptune discussed below) which is in essence nothing else than the humanitarian core of a culture embedded both in personal and social morality keeping the society together in real and local bonds similar to that of fraternity, that is, in its broadest expression that of humanity.

Thus when Dworkin is referring to political institutions and principles which make up a rule of law, he is asserting, in accordance with his lines of interpretive theory that, there cannot be any such textural setting of political institutions decided and acknowledged beforehand without interpretive, -that is, intellectual- participation in the process, which surely comes from a cultural way of life bearing within itself various problems and their resolutions that require this very process which is actually to be determined by this culture, that is again, by the certain way of living which appears to be in personal cases, the integrity of a person's life differing him from another individual, or in broader perspective differing a family from another and in the final stage differing a culture from another which are all kept together in one distinct pattern than from another by the coherence of a concept of integrity. Therefore any such setting would be similar to the case of an actor "quoting", as mentioned above, who is certainly quoting from a text written by someone else, and what's more with a purpose in mind! That is, even in the case of a quoting actor, when he is quoting from a certain text of that essence, he (and each actor) would be doing this in his own way and that actually makes acting a product of culture differing in each case. Thus there is no decided textual setting of political institutions each actor should obey -or in other words in a far more strict sense must be made to comply to- which actually as mentioned above shall take place differently in different cultures even if such uniform copying process were forced up to !. As a conclusion the cultural setting of local, fraternal and humane bonds making up a certain community shall determine these political institutions in regards to its past and form (elements of fit) and furthermore shall check this pre-interpretive stage of its determination in the interpretive stage whether it can be justified on grounds of rationality (element of soundness) which certainly brings forward with itself another but a refined concept of justification beyond the pattern compromised upon and complied to in this second stage. 
This point is actually the core of the argument why Dworkin tries to implement that pragmatism is not a sufficient concept of legal rationale depend ig each time on different conceptions of a concept which are actually incompatible with one another when tested on this core of initial standing of "integrity" as a whole, which must be the initial stand-point of view as we declare it now in the third stage of post-interpretive act where the lackage is observed to be coming from!

Thus returning now back to the simplier version of our interpretive process, we can say that justification of all three stages ought to be done in the best possible light ever possible; so the question is -can we, considering the initial proposition of this argument, impose any purpose we like upon an object? Actually, the respond ought to be clear from the above explanation but if we are to put it in this generalised context, it is surely that the "history and the form" of the object, in parallel to the cultural setting of a community in fraternal patterns mentioned above, proposes a natural constraint upon the purpose to be exercised on our object. Thus, as mentioned in the introductory, even if ultimate rationale were supposed to be provided in our purpose somehow, still that utmost standing would confront a natural constraint, impossible to be overwhelmed even by the most supportive good intentions. Again the question is -shall we say alas! or not bearing within itself various replies depending on the integrity of the way of the world we actually live in, depending on the integrity of our personal approaches to that world and the way it is, and finally depending on the integrity of different approaches that may be possible in regards that very same world and the way it is; which is actually the point Dworkin is referring to when he is asserting that even if differences of opinion are observed in the compromising process, "each point of view must be allowed a voice in the process of deliberation but the collective decision must nevertheless aim to settle on some coherent principal whose influence then extends to the natural limits of its authority."3

Thus this coherent principal whose influence (then) extends to the natural limits of its authority, is the mere independent factor of this interpretive process, observed, that is, taking place in the post-interpretive stage -yet embedded somewhere beyond the sta.

3. Dworkin, R. Law's Empire, Fontana Press, 1986, p. 179. 
ges- even stage three- as the spatial situation of Neptune in the Solar System Dworkin refers to as "whose orbit lays beyond those planets already recognised but could well explain the behaviour of the nearest planets"4, which is actually nothing more than the utmost rationale of humanity and fraternity giving shape to all kinds of social relations, like that of friendship, family and even that of political community and what is more which is independent of their former and present standing (in the way of history and form) as well as various purposes offered to be implemented on these relations -observed to be competing with each other in the compromising process- actually to which we would have no resolution if it were not for this final and independent element of integrity, in Dworkin's words Our Neptune which perhaps ought to be the Sun of our solar system which Neptune partly shares the pride with since it seems to be the final planet within reach for us, for Earthians, as far as a more general solar system is concerned that of Sun.

Thus returning to our starting point at the beginning of this paragraph, although the third element is independent of both the elements of fit and sound, Sun symbolises the most supportive good intentions which are actually out of reach and which must be converted to a Neptune within reach yet in configuration; that is in Dworkin's words again "we all enter the history of an interpretive practice at a particular point", not a point that of our like or wishing! That is again, we interpret the world we live in as best we can, that is up to Neptune at best and keep on doing this being aware of the fact that we shall never be able to reach the Sun and can actually never be able to experience interpreting another world of our like or wishing; so at this very point DaviesHoldcroft is wrong to assert that "the interpreter is catapulted straight into Plato's cave."

Thus quoting Dworkin again, "We need assumptions or convictions about what counts as part of the practice in order to define the raw data of this interpretation at the pre-interpretive stage. The interpretive attitude cannot survive unless members of the same interpretive community share at least roughly the same assumptions about this. We also need convictions about how far the justification

4. Dworkin, R. Law's Empire, Fontana Press, 1986, pp. 183-184.

5. Dworkin, R. Law's Empire, Fontana Press, 1986, pp. 90-91.

6. Davies, H.-Holdcroft, D. Jurisprudence: Texts and Commentary, Butterworths, 1991, p. 382 . 
we propose at the interpretive stage must fit the standing features of the practice to count as an interpretation of it rather than the invention of something iew. Only history can teach us how much difference is too much."

And once again remembering our starting point and arguments let us quote Dworkin and then Davies-Holdcroft in regards these points following Dworkinian lines: "Social rules do not carry identifying labels! But a very great degree of consensus is needed if the interpretive attitude is to be fruitful, and we may therefore abstract from this stage in our analysis by pre-supposing that the classifications it yields are treated as given in day-to-day reflection and argument." "The second stage, the actual stage of interpretation, provides a justification for the social practice. But such justification is constrained by a dimension of fact; the interpretive justification of the social practice must have some degree of fit with the data it interprets. However, as we see, the fit need not be perfect. Furthermore the dimension of value acts as a constraint upon interpretation, in that it tests the acceptability of certain convictions about the kinds of justification that show the data in the best light."

For the exemplary of Neptune and Sun, Dworkin is quoting the very same pattern forming the basis of his theory thus; "We need some account of how the attitude I call interpretive works from inside, from the point of interpreters. Unfortunately, even a preliminary account will be controversial, for if a community uses interpretive concepts at all, the concept of interpretation itself will be one of them: a theory of interpretation is an interpretation of the higherorder practice of using interpretive concepts. (So any adequate account of interpretation must hold true of itself) 10

In the same regards again, Dworkin is asserting that "Governments have goals: they aim to make the nations they govern prosperous or powerful or religious or eminent; they also aim to remain in power. They use the collective force they monopolise to these and other ends." And "Law insists that force not be used or withheld, no matter how useful that would be to ends in view, no matter how

7. Dworkin, R. Law's Empire, Fontana Press, 1986, pp. 67-68.

8. Dworkin, R. Law's Empire, Fontana Press, 1986, pp. 65-66.

9. Davies, H..Holdcroft, D. Jurisprudence: Texts and Commentary, Butterworths, 1991, p. 377.

10. Dworkin, R. Law's Empire, Fontana Press, 1986, p. 49. 
beneficial or noble these ends, except as licensed or required by individual rights and responsibilities flowing from past political decisions about when collective force is justified."11

$\mathrm{He}$ is going on further saying that, "Integrity means patterns of behaviour acting according to convictions that inform and shape our lives as a whole, that is, rather than capriciously or whimsically." "This ability is an important part of our more general ability to treat others with respect, and it is therefore a prerequisite of civilisation." 12 Then again, "Integrity, rather than some superstition of elegance (that of Sun, maybe!) is the life of law as we know it!"'3

That is again, "A state that adopts the(se) internal compromises is acting in an unprincipaled way, eventhough no single official who voted for or enforces the compromise has done anything which judging his individual actions by the ordinary standards of personal morality, he ought not to have done."14 That is, Neptune symbolises the planet of "State", "founded upon common principals, not upon rules hammered out in political compromise, at the very moment when individuals accept that their fates are linked in this strong way" through common principals. ${ }^{15}$

Thus "they treat relations among themselves as characteristically, that is also on egalitarian grounds, not just spasmodically. Integrity insists that each citizen must accept demands on him and may make demands on others, that share and extend the moral dimension of any explicit political decisions and thus fuses citizens' moral and political lives." 16

Thus "the State lacks integrity because it must endorse principals to justify part of what it has done that it must reject to justify the rest", else than the single official's act mentioned above. ${ }^{17}$

Finally "the structure and hierarchy must reflect the group's assumption that its roles and rules are equally in the interest of all,

11. Dworkin, R. Law's Empire, Fontana Press, 1986, pp. 92-94.

12. Dworkin, R. Law's Empire, Fontana Press, 1986, pp. 165-166.

13. Dworkin, R. Law's Empire, Fontana Press, 1986, pp. 166-167.

14. Dworkin, R. Law's Empire, Fontana Press, 1986, pp. 183.184.

15. Dworkin, R. Law's Empire, Fontana Press, 1986, p. 211.

16. Dworkin, R. Law's Empire, Fontana Press, 1986, pp. 189-190.

17. Dworkin, R. Law's Empire, Fontana Press, 1986, p. 184. 
that noone's life is more important than anyone else's" to be left outside in regards the results of the compromising process. ${ }^{18}$

And now concluding our arguments, it must be obvious that from an other point of view, following these quotations making up the textual material, it is up to the reader, that is again the interpreter, with the qualifications imposed upon him by the ideal of integrity as a whole, to justify the textual material rationally in the interpretive stage and furthermore to check it out in the postinterpretive stage stripping off himself from whatever he might be influenced in the compromising stage (that of stage two) as in the form of a differing opinion of his own competing with others in regards the "object" whatever that might be, -surely from this point of view our interpretation of Dworkinian interpretive stages -within a community of common principals making up the mere composition of integrity united thus and above the lines drawing the borders of that community. For me it is that, one cannot keep the good and the less good together as observed in the compromising process of various modifications, since we ought to seek and comply with the "good" beyond all these alternatives in the postinterpretive stage of our interpretive task, which naturally ought to be commonly acknowledged in regards our cultural way of life in integral terms. But again, if there is no cultural flourishment, it is in vain to hope for an integrally full life of morality either in persons' lives or in that of society! Wooden-legs, crabbed heads and vulgar girls, that is humanity -corrupted- on the whole wouldn't do!

18. Dworkin, R. Law's Empire, Fontana Press, 1986, p. 200. 